\title{
Detection of Sangeang Api Volcano Ash Cloud Based on Remote Sensing Image
}

\author{
Jiangshan Dong, Chengfan Li*, Jingyuan Yin, Junjuan Zhao, Dan Xue \\ School of Computer Engineering and Science, Shanghai University, Shanghai, 200444, China \\ *Corresponding author e-mail: lchf@shu.edu.cn
}

\begin{abstract}
Large-scale volcanic ash clouds can threaten the safety of increasingly prosperous aviation transportation. The current recognition of the ash cloud mainly relies on the remote sensing technology. Taking the moderate resolution imaging spectroradiometer (MODIS) images of Indonesia Sangeang Api volcanic ash clouds as data source on May 30, 2014, this paper put forward the use of split window light temperature for detection of the volcanic ash cloud, which is based on the analysis of the physical properties of volcanic ash cloud and the absorption spectral characteristics in the scope of thermal infrared bands. The result shows that the split window light temperature difference algorithm can effectively identify the spatial distribution of the volcanic ash clouds, and has some potential for applications in improving the effect of the ash cloud recognition and disaster prevention and mitigation.
\end{abstract}

Keywords-remote sensing, split window light temperature difference, volcanic ash cloud, Sangeang Api volcano

\section{INTRODUCTION}

The ash clouds mainly include volcanic clastic particles and gas composition $[1,2]$. A massive cloud ash can not only cause a major change in the global climate and environment system such as ozone depletion, air pollution, the greenhouse effect, acid rain and the abnormal air temperature, rainfall and so on [3-5], but also the floating height of ash cloud generally located in the stratosphere where aircrafts fly, which is easy to bring about aviation safety accidents. Due to the sudden of volcanic eruption and the uncertainty of the drift of volcanic ash clouds, the location, strength, height and range of the forming of the ash cloud are difficult to accurately predict out $[6,7]$. Once it breaks out, it most likely threats the homeland security of related country, and along with the opening of international routes, the possibility of threats of aircraft encountering the ash will also increase. At present, an effective method for ash cloud recognition is the use of satellite remote sensing technology. Remote sensing is an effective method to estimate the temperature of the earth's surface and to detect the surface heat source; it possesses the advantages of wide coverage and high resolution. The world's first weather satellite TIROS succeeded in its launch since April in 1960, there are increasing numbers of thermal infrared remote sensing sensor types carried on satellite, resolution is also increasing. Although thermal infrared remote sensing obtained widespread application in areas such as air pollution and detection for change of sea surface temperature, but its application in the study of the ash cloud detection is still relatively small, as are the research results.

The ash cloud monitoring using remote sensing technique is a huge system project, including which how to accurately identify the spatial distribution of the ash cloud is the key to the whole monitoring system. Although the researchers at home and abroad used all kinds of remote sensing data and methods for identification study on some large-scale volcanic ash cloud [8], but most of these methods are based on the mathematical model, and can't completely meet the requirements of actual ash cloud recognition, besides they also have certain uncertainty. Volcanic ash cloud is mixed with a large number of volcanic debris particles, can form the unique absorption spectrum features. Based on this, according to the remote sensing characteristics of the ash cloud, with MODIS remote sensing image as data source, this paper proposes using the split window light temperature difference algorithm to identify the ash cloud on May 30, 2014 Indonesia Sangeang Api volcano, which can provide certain reference for the monitor of other cloud ash and for the research of diffusion prediction model.

The first section of our paper is the introduction. The second section is the theoretical basis and the third section is the thermal infrared remote sensing inversion method of volcanic ash cloud. The fourth section is volcanic ash cloud detection of Sangeang Api volcano. The last section is our conclusion.

\section{THEORETICAL BASIS}

\section{A. Definition of the ash cloud brightness temperature}

Brightness temperature refers to the blackbody temperature when the spectral radiation degree of actual object within a certain wavelength is equal to that of the absolute blackbody within the same wavelength $[9,10]$. The definition of brightness temperature of the ash cloud is the same, its mathematical expression is:

$$
\varepsilon(\lambda, T) \cdot \frac{c_{1}}{\pi} \lambda^{-5}\left[\exp \frac{c_{2}}{\lambda T}-1\right]^{-1}=\frac{c_{1}}{\pi} \lambda^{-5}\left[\exp \frac{c_{2}}{\lambda T_{s}}-1\right]^{-1}
$$

In the formula $\lambda$ refers to the wavelength (The unit is $\mu \mathrm{m}) ; \varepsilon$ $(\lambda, T)$ refers to spectral emissivity of actual object when the 
temperature is $T$ and the wavelength is $\lambda$, the range of values is between 0 and $1 ; \mathrm{C}_{1}$ refers to the first radiation constant, $\mathrm{C}_{1}=3.7418 \times 10^{-16} \mathrm{~W} \cdot \mathrm{m}^{2} ; \quad \mathrm{C}_{2}$ refers to the first radiation constant, $\quad \mathrm{C}_{2}=1.438 \times 10^{-2} \mathrm{~W} \cdot \mathrm{k} ; \mathrm{T}$ refers to the real temperature of the actual object (the unit is ${ }^{\circ} \mathrm{C}$ ); $\mathrm{T}_{\mathrm{s}}$ refers to the brightness temperature of the absolute blackbody (The unit is $\mathrm{k})$.

Often we use the thermal infrared remote sensing data to invert the temperature of the top of cloud, the surface of the earth, the surface of the sea. When the ash cloud erupts into the stratosphere, carrying a large amount of heat, water vapor and volcanic clastic particles, etc., it makes that the brightness temperature of the top of the cloud is higher than that of the surrounding meteorological cloud. At present, the use of satellite remote sensing technology can only detect the temperature of the top of the ash cloud, it cannot capture its internal temperature, and the capture of its internal temperature often relies on going to the field by means of survey aircraft or other methods.

\section{B. Remote sensing inversion principle of ash cloud brightness temperature}

The template is used to format your paper and style the text. All margins, column widths, line spaces, and text fonts are prescribed; please do not alter them. You may note peculiarities. For example, the head margin in this template measures proportionately more than is customary. This measurement and others are deliberate, using specifications that anticipate your paper as one part of the entire proceedings, and not as an independent document. Please do not revise any of the current designations.

In general, any objects in the nature with temperature higher than temperature of thermodynamics (Kinetic temperature) are constantly emitting outward. When the temperature increases, the total radiation energy increases, maximum wavelength gradually shortens, and vice versa.

The Planck's law shows that the calculating formula of blackbody radiation intensity is:

$$
B_{\lambda}(T)=\frac{h c^{2}}{\lambda^{5}\left(e^{h c / \lambda k T}-1\right)}
$$

In the formula $\lambda$ refers to the wavelength (The unit is $\mu \mathrm{m}$ ); $h$ refers to Planck's constant; $h=6.6260693 \times 10^{-34} \mathrm{~J} \cdot \mathrm{s} ; \mathrm{c}$ refers to the speed of light, $\mathrm{c}=3 \times 10^{8} \mathrm{~m} / \mathrm{s} ; k$ refers to the Boltzmann constant, $\mathrm{k}=1.3806505 \times 10^{-23} \mathrm{~J} / \mathrm{K} ; T$ refers to thermodynamic temperature (The unit is $\mathrm{k}$ ).

When temperature is known, we can obtain the distribution of energy spectrum of the object and then calculated peak wavelength of energy spectrum. Conversely, when we know the features of energy distribution and the radiation intensity, we can also deduce the actual temperature of the object. This is the remote sensing inversion theory foundation cloud brightness temperature. In practice, when we conduct the ash cloud brightness temperature remote sensing inversion, usually use the thermal infrared channel of wavelength in the range of $10.3-12.5 \mu \mathrm{m}$.

\section{THERMAL INFRARED REMOTE SENSING INVERSION METHOD OF VOLCANIC ASH CLOUD}

Since the advent of thermal infrared remote sensing technology, the researchers began to constantly try to use satellite thermal infrared remote sensing data to invert the brightness temperature of the surface of the earth. Since then, with the progress of remote sensing sensor technology and applied research gradually thorough, on the basis of assumptions and approximation of the proposed various atmospheric path radiation equation, there appeared the radiation transmission equation method, the algorithm of single channel, single window algorithm, split window algorithm, multi-angle algorithm and some improved algorithms [8]. Among them, the split window light temperature difference algorithm has the properties of simple calculation, high precision, so that it is widely applied in the practical application.

Split window light temperature difference algorithm is based on thermal radiation data of at least two thermal infrared bands captured by remote sensing sensor, it uses the absorption rate difference of the atmospheric window $(11-13 \mu \mathrm{m})$ near two wavelengths $(11 \mu \mathrm{m}$ and $12 \mu \mathrm{m})$, especially the difference of absorption of water vapor in the atmosphere to eliminate atmospheric effects, and use the linear combination of the brightness temperature of the two bands to calculate temperature. Usually it applies to sensors with two adjacent thermal infrared bands. For example, MODIS, visible and infrared radiometer, advanced very high resolution radiometer, etc.

The radiative transfer equation of thermal infrared band on the remote sensing sensor is:

$$
\left\{\begin{array}{l}
T_{b 1}=T_{s}\left(1-\tau_{1}\right)+K_{1} \int_{0}^{h} d z \rho T_{a}\left(z_{T}-z\right) \\
T_{b 2}=T_{s}\left(1-\tau_{2}\right)+K_{2} \int_{0}^{h} d z \rho T_{a}\left(z_{T}-z\right)
\end{array}\right.
$$

By substitution of $\tau_{\lambda}=K_{\lambda} \int_{0}^{h} d z \rho(z)$ in formula (3), we can get:

$$
T_{s}=T_{b 1}+\frac{T_{b 1}-T_{b 2}}{K_{2} / K_{1}-1}
$$

In the formula $T_{\mathrm{b} 1}$ and $T_{\mathrm{b} 2}$ refer to the brightness temperature of two adjacent thermal infrared bands respectively, $\tau_{1}$ and $\tau_{2}$ refer to the optical thickness of two adjacent thermal infrared bands respectively, $h$ refers to the flying height of the remote sensing sensor, $\rho$ refers to air density, $K_{1}$ and $K_{2}$ refer to the radiation absorption constant of two adjacent thermal infrared bands respectively, for different remote sensing sensors, the selection of the adjacent bands is 
also different, $T_{\mathrm{a}}$ refers to the temperature of the air, $T_{\mathrm{s}}$ refers to the temperature of the ground.

Formula (4) can be further simplified as follows:

$$
T_{s}=A_{0}+A_{1} T_{b 1}+A_{2} T_{b 2}
$$

In the inversion of land surface temperature, we need to know the values of the surface emissivity $\varepsilon$ and $A_{0}, A_{1}, A_{2}$ in advance, while the values of $A_{0}, A_{1}$ and $A_{2}$ are determined by atmospheric conditions as well as the surface emissivity $\varepsilon$. So it can be further simplified as follows:

$$
T_{s}=1.274+\frac{P\left(T_{a}-T_{b}\right)}{2}+\frac{M\left(T_{a}+T_{b}\right)}{2}
$$

In the formula, $P=1+\frac{0.156(1-\varepsilon)}{\varepsilon}+0.482 \frac{\Delta \varepsilon}{\varepsilon^{2}}$, $M=6.26+\frac{3.98(1-\varepsilon)}{\varepsilon}+38.33 \frac{\Delta \varepsilon}{\varepsilon^{2}}, \quad \varepsilon$ refers to the average emissivity of two thermal infrared bands, $\Delta \varepsilon$ refers to the difference of the average emissivity of two thermal infrared bands. In the process of actual calculation, we just need to know the average emissivity $\varepsilon$ of two thermal infrared bands and their difference $\Delta \varepsilon$ in the thermal infrared remote sensing sensor, on average, so that the inversion results of brightness temperature of high precision can be obtained.

\section{VOLCANIC ASH CLOUD DETECTION OF 2014 SANGEANG API}

After the text edit has been completed, the paper is ready for the template. Duplicate the template file by using the Save As command, and use the naming convention prescribed by your conference for the name of your paper. In this newly created file, highlight all of the contents and import your prepared text file. You are now ready to style your paper; use the scroll down window on the left of the MS Word Formatting toolbar.

Sangeang Api, also known as Abigail volcano, is located in Indonesia, and it's also a volcanic island. It is a part of the Lesser Sunda Islands, and it is governed by the West Nusa Tenggara. It is a stratovolcano composed by two volcanic cones, the altitudes of which are 1795 meters and 1949 meters respectively, and it is one of the most active volcanos in Lesser Sunda Islands. The ash erupted in May 30, 2014 reached up to $15-20 \mathrm{~km}$ (Fig.1), flew over the ocean, arrived in the Kimberley region in the northwest of Australia and affected many flights in the local area.

This paper uses the Terra/MODIS satellite remote sensing data of the eruption in May 30, 2014 to detect and study volcanic ash clouds. Fig. 2 is MODIS false color composite image of bands 2, 1, 3 on May 30, 2014, and the center wavelengths of three corresponding bands are $0.859 \mu \mathrm{m}$, $0.645 \mu \mathrm{m}$ and $0.469 \mu \mathrm{m}$ respectively.

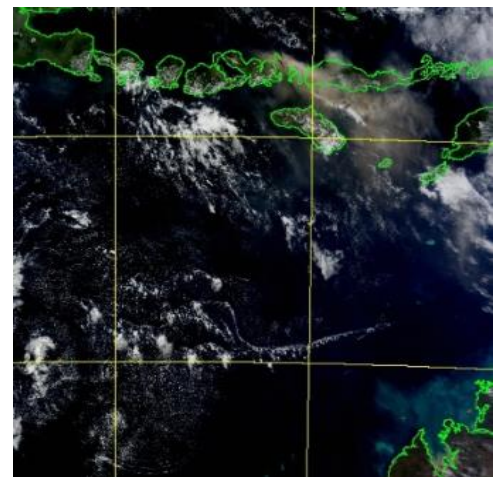

Fig. 1. MODIS volcanic ash cloud of Sangeang Api on May 30, 2014

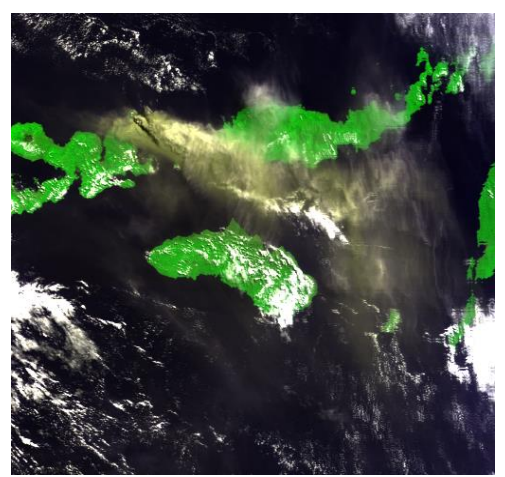

Fig. 2. MODIS false color composite image of the volcanic ash clouds of Sangeang Api

Seen from Fig. 2, the color of the ash cloud and the ice layer covered by the ground are close to the color of seawater and it is difficult to distinguish visually. The diffusion direction of the ash cloud is mainly southeast when the ash cloud diffused into the sky by wind.

The above analysis shows that the volcanic ash cloud contains large amounts of volcanic debris particles, so the absorption characteristic of the ash cloud in the thermal infrared spectral range is different from that of the ice, water and other surface. Thus, according to the actual condition of the distribution of ground objects near the Indonesian Sangeang Api volcano, we selected water and ash constituents to conduct the comparison and analysis of the spectral absorption characteristics.

Within the scope of the thermal infrared band, the capacity of spectral absorption of ash cloud composition decreases rapidly with the increase of wavelength, while the ability of the spectral absorption of water and ice is rapidly increasing with the increase of the wavelength. Generally speaking, for the ash cloud, the brightness temperature value of the MODIS remote sensing sensor on thermal infrared band $31(10.78-11.28 \mu \mathrm{m})$ and thermal infrared band $32(11.77-12.27 \mu \mathrm{m})$ is negative; while for water and ice, the value of the difference between two thermal infrared channels is positive. Therefore we can make use of the spectral absorption characteristic differences of ice, water, and the ash cloud composition in the MODIS sensor adjacent 31, 32 bands to recognize the ash cloud. The results of the ash cloud recognition obtained by the split window brightness temperature difference algorithm are shown in Fig. 3. 


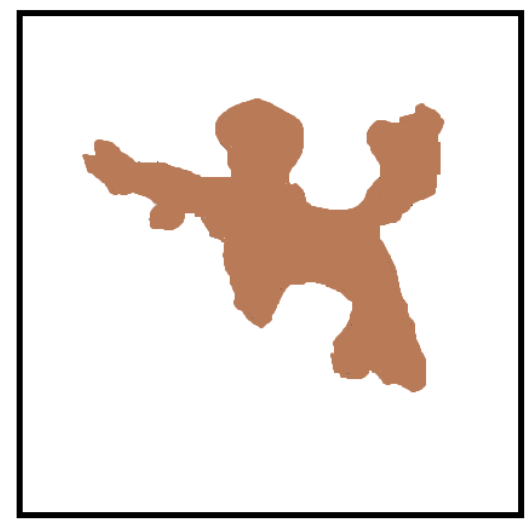

Fig. 3. Volcanic ash clouds of Sangeang Api obtained with the split window brightness temperature difference algorithm

When the Indonesian Sangeang Api volcano was in the early stage of its eruption, the ash clouds were on a smaller scale. However, with the increase of the amount of eruption, volcanic ash clouds began to accumulate, and under the action of wind, the cloud began to drift and diffusion, the volcanic ash cloud began to change shape, gradually became narrow and spread to southeast direction. Seen from Fig. 3, the use of split window bright temperature difference algorithm can accurately detect the space form distribution of the ash cloud, and the detected distribution of the ash cloud can reflect the diffusion trend of the ash cloud. In addition, there was certain noise in the identified volcanic ash cloud, according to the analysis, this may be due to the low spatial resolution of remote sensing sensor and low temperature of the top cloud caused by high clouds, but it does not affect using remote sensing technology for our study on the detection of volcanic ash clouds.

\section{CONCLUSION}

The volcanic ash cloud will not only bring about the change of global climate and environment, but also seriously threaten the aviation transportation safety. The ash cloud contains a lot of volcanic clastic particles, with special characteristics of absorption spectrum. In this paper, by analyzing the absorption spectrum characteristics of the ice, water, volcanic ash composition in the thermal infrared band, we found the spectral characteristics of the ash decreases with the increase of the wavelength, this is just the opposite to the absorption spectrum characteristics of water and ice in the thermal infrared band. This feature can be used to better identify the ash cloud from the remote sensing images. Based the Indonesia Sangeang Api volcanic ash clouds on May 30, 2014, taking the thermal infrared band of remote sensor Terra/MODIS as data source, this paper comprehensively utilized the spectral characteristics of absorption spectrum of the ash clouds in the thermal infrared band to help recognize the ash clouds. It turned out that split window light temperature difference algorithm can accurately identify the space distribution of the volcanic ash clouds from the MODIS images.

In addition, for different types of volcanoes, there were some differences in mineral composition and chemical properties, the absorption spectral characteristics of such ash clouds are not completely consistent with absorption spectral characteristics in this article. This requires that for different types of volcanoes, we need to separately calculate the specific absorption spectrum feature of the ash cloud in thermal infrared band according to the actual situation. When we conduct the identification of the volcanic ash clouds, on the one hand, the algorithm of split window brightness temperature difference is mainly based on MODIS data, whether it can be used for other satellite remote sensing data has yet to be further verified; on the other hand, when we apply the algorithm of split window brightness temperature difference to recognize the volcanic ash clouds, because of the physical and chemical characteristics and the surrounding environment of the ash clouds, there exist many other recognition factors such as moisture, volcanic ash clastic particles, surface vegetation coverage condition, etc. This requires that in the future study of volcanic ash clouds; we should give full consideration to other recognition factors, in order to better improve the accuracy of ash cloud recognition.

\section{ACKNOWLEDGMENT}

The authors thank the vital comments and suggestions made by the anonymous reviewers and editorial team. This work was co-supported by the Projects of National Science Foundation of China (41404024), Shanghai Science and Technology Development Foundation (14231202600), Laboratory Technician Team Building Program in Shanghai Universities (B.60-E108-14-101) and Young Teachers Training and Supporting Plan in Shanghai Universities (2014-2016).

\section{REFERENCES}

[1] G.P. Ellrod and A.J. Schreiner, "Volcanic ash detection and cloud top height estimates from the GOES-12 imager: Coping without a $12 \mu \mathrm{m}$ infrared band", Geophy Res Lett, vol.31, no.15, pp. 1-4, 2004.

[2] G. Gangale, A.J. Prata and L. Clarisse. "The infrared spectral signature of volcanic ash determined from high-spectral resolution satellite measurements", Remote Sens Env, vol.114, no.2, pp. 414-425, 2010.

[3] K.R. Papp, K.G. Dean, J. Dehn, "Predicting regions susceptible to high concentrations of airborne volcanic ash in the North Pacific region", J Volcano Geoth Res, vol.148, no.3-4, pp. 295-314, 2005.

[4] A.J.Prata, "Satellite detection of hazardous volcanic clouds and the risk to global air traffic", Nat Hazard, vol. 51, no.2, pp. 303-324, 2009.

[5] A.J. Prata, "Observations of volcanic ash clouds in the $10-12 \mu \mathrm{m}$ window using AVHRR/2 data", Int J Rem Sens, vol.10, no.4-5, pp. 751-761, 1989.

[6] P.E. Gary, "Impact on volcanic ash detection caused by the loss of the $12.0 \mu \mathrm{m}$ Split Window band on GOES imagers", J Volcano Geoth Res, vol. 135, no.1-2, pp. 91-103, 2004.

[7] F. Ding and H.Q. Xu, "Sensitivity analysis of mono-window and singlechannel algorithms to the possible errors in parameter estimation", Sci Sur Map, vol. 32, no.1, pp. 87-95, 2007.

[8] Z.H. Qin, A. Karnieli, and P. Berliner, "A mono-window algorithm for retrieving land surface temperature from Landsat TM data and its application to the Israel-Egypt Border Region”, Int J Rem Sens, vol. 22, no.18, pp. 3719-3746, 2001.

[9] J.C. Price, "Land surface temperature measurements from the split window channels of the NOAA 7 advanced very high resolution radiometer", J Geoth Res, vol. 89, no. D5, pp. 231-237, 1984.

[10] F. Becker and Z. Li, "Towards a local split window method over land surface”, Int J Rem Sens, vol. 11, no. 3, pp. 369-393, 1990. 